\title{
Supporting Students at a Distance
}

\section{Global Threats, Local Protections, and Ethical Obligations}

Donald J. D. Mitchell, Union School of Theology

\begin{abstract}
This paper looks at the experience of Union School of Theology, and specifically the library service, in supporting distance students studying at undergraduate, postgraduate and research levels. Consideration is given to the challenges of resource provision, copyright and information literacy. The case study explores solutions developed through practice and experience, notes the benefits of structures and technologies that engage the students, and considers lessons learned from the particular model adopted. The conclusion emphasises the necessity of equivalence of student experience, whether on or off campus. Emphasis is placed on the role of librarians and teaching faculty in theological institutions as partners in the development and equipping of students as life-long learners.
\end{abstract}

\section{SEMINARY CONTEXT}

Recent years have been hard for seminaries and theology departments in the UK. Recruitment, particularly, but not only, for nondenominational institutions, has been variable and at times very poor. Reduced incomes from students, rising costs, and increased government bureaucracy (QAA, UK Border Agency visa regulations, and funding body requirements) have increased local administrative costs and further impacted recruitment, both domestically and internationally. Whilst one cannot ignore local, internal factors, these pressures must be considered major factors in the spate of closures and course revisions that affected our sector over recent years-the closure of ICC in Glasgow and the retrenchment of undergraduate courses at Redcliffe in Gloucester and St. John's in Nottingham being clear examples. 
Union School of Theology (UST) has not been immune to these pressures and, indeed, there have been times over the seven years since I joined the institution when we have wondered whether we would survive. The school has a history going back to the early 20th century when, following the 1904 revival, Bible colleges were established at Porth in the Rhondda and Barry on the S. Wales coast. These combined and then, in the 1970s, the college moved to its present campus at Bridgend between Cardiff and Swansea as the Evangelical Theological College of Wales (ECTW) and subsequently offered degrees franchised from various universities as the seminary and university needs changed. A change in principal resulted in a further name change to Wales Evangelical School of Theology (WEST), with further shifts to other franchising institutions. As WEST, we also entered partnership arrangements with SaRang Community Church in Seoul, South Korea, which started to involve the school more directly in church planting and missions. Then, during the last three years, we became UST, part of a wider, more holistic ministry that looks beyond purely educating ministers and missionaries and seeks to provide wider support for the confessional church through resource creation, research, and support for church planting, as well as academic education up to and including PhDs. We currently offer our degrees through the OU at the taught level and through the Free University, Amsterdam at research (PhD) level.

Throughout this period, UST has sought to reach out to the church in a wide, non-denominational way and without geographic limits (as government regulations allowed). However, this did not result in the same level of recruitment as had obtained in the period up to circa 2010. Distance learning (DL) models had been developed that enabled students to study to degree level but, whilst they came to number about the same in absolute terms as campus students, they rarely formed a major element of provision from a library perspective, usually working alone and developing their own local resource support. Since 2010, student recruitment for both campus and DL declined markedly and the school's management, in consultation with faculty, sought to develop a model of provision that would appeal more to a demographic that was perhaps reluctant to move, engaged in existing ministries that they didn't wish to leave, or simply unable to afford the cost of full-time study. As WEST, we had developed a one-year bridge course (Graduate Diploma (GDip)), campus-based and designed to lead candidates into our master's 
programmes. This suffered the weakness of the longer BA/BD, in that it required physical relocation and all the consequent costs that went with it, although clearly benefitting from the access to faculty and library facilities on campus. In reflecting upon this particular element of our provision, it was decided to use it as the vehicle to deliver high quality, L6 (i.e., final year undergraduate teaching) theology at local level, but addressing the need for peer support and theological guidance through establishing regional learning centres.

Churches, church groupings, and other appropriate organisations can apply to be learning centres (LC). Each needs to have a lead mentor who is academically, theologically, and confessionally equipped to work with us and the students in pursuing not only the level of study, but also aligning with the core values and mission of the school. Students gather once a week to receive teaching via video sessions on the module they are studying, to use resources held centrally by the LC, and to discuss issues arising in their studies with each other and the lead mentor. Currently, we have about 13 LCs, six of which are overseas in Europe and North America.

\section{CHALLENGES FOR THE SCHOOL \& LIBRARY}

Clearly, developing such a model, although not unique (it has strong parallels with Open University (OU) models, which make our current franchise arrangements highly appropriate), presents a variety of challenges at both the institutional level and for the library. Institutionally, the preservation of quality, particularly in the light of distance delivery higher education (HE) failures in previous years, is a major factor. The vetting of LCs and mentors is critical to the integrity of the programme, equivalence of experience is a key element in ensuring quality, whilst the students work under different contextual constraints their overall experience must equate to that of the campus based students.

As all the teaching comes from UST, there has been a heavy demand on central services to provide good-quality teaching materials, especially videos, and this has required staff to learn new skills in teaching through video, which, for those of you who haven't tried it, is really not as easy as you might think! The lack of student interaction and feedback, requirements of pacing, physical stance, and facial expression all have a significant bearing on the quality—or otherwise-of the product, along with scripting and the ability to 
read a script whilst appearing and sounding natural. Issues of the equivalence of learning experience must also be considered, and these have particular impact on library provision, of which more later. The integrity of an individual's work, especially with reference to assessment, has also to be considered.

\section{LIBRARY RESOURCES \& RESOURCING}

The most obvious disadvantage for students who are geographically remote from UST is the lack of access to the physical resources of the institutional library. This is compounded by the inevitable limits the institution places on core materials that are either too scarce or too valuable to lend.

The strategy adopted to deal with this developed as the model developed. Our initial partner centre was the North West (NW) Partnership, a co-operative of evangelical churches with a centre in Liverpool. Having previously partnered with Oakhill College, they already had a small, relevant collection of materials, along with a substantial collection from the Northern Evangelical Library and, subsequently, we were able to donate some titles. However, most LCs do not start up with such strength, so, early on, part of the partnership agreement was that the LCs should purchase one each of the core module titles to provide the GDip students with a central reference resource. Experience over two to three years has led us to amend this to require the students themselves to obtain (by whatever means) their core texts, whilst the LCs develop, wherever possible, a bank of wider resources. This has been partly, although patchily, aided by the library's ability to distribute surplus publications derived from a fairly prolific, if irregular, stream of donations.

For wider reading, mentors and students are encouraged to locate libraries that can provide practical support. If necessary, I will contact seminary libraries and establish the conditions under which they will allow (if at all) access to their collections. With larger HE institutions, the students are expected to explore the options themselves. Sadly, we no longer have access to the SCONUL scheme (an HE cooperative library scheme working amongst UK publicly funded and other institutions), which creates a greater burden on our DL students than would have otherwise been the case. Public library use, particularly interlibrary loans (ILL), with an emphasis on national- and British Library (BL)-level searching, is also advised. 
Public libraries may (for cost reasons) not make users aware of the higher level services for ILL; hence, part of my role has been to brief mentors and students on the availability of these options. In the last resort, and only where restrictions permit, postal loan is provided from the library at UST, or relevant sections (within copyright allowance) are sent digitally.

Until recently, my own misunderstanding of the e-book supply mechanisms, along with cost elements, precluded purchasing e-books. However, a highly constructive chat with a commercial representative in early 2018 led to further investigation. $60-80 \%$ of most core titles turned out to be available digitally, and a growing income stream through donation has allowed us to implement a purchase programme of e-books tailored to the module content. Prior to this development, e-texts were available, albeit of a somewhat elderly nature, through Theology-on-the-Web-an internet site digitising older theological materials now out of copyright. More recent material was also obtained by direct permission from self-publishing authors such as Habermas to place their publications on our virtual learning environment (VLE). Additionally, the Copyright Licensing Agency (CLA) license scheme allowed the provision of many core readings through the VLE, although this could never be entirely satisfactory, as the extracts were limited and did not allow immediate wider contextual reading, and they place a considerable burden on my own role in terms of digitization and copyright compliance. Where available, e-books address both these issues!

Journal access is less problematic. The library at UST offers both e-journals and a digitization service for items not accessible electronically to all students. This has been underpinned by an active policy of obtaining as many hardcopy journal runs as I can, although the consequent pressure on space is something of an issue! When all else fails, I have appealed to the Association of British Theological and Philosophical Libraries (ABTAPL) network, and this has largely filled the gaps. I am extremely grateful to all who have responded to my pleas so positively over the years, including several US institutions!

Digital access has also been strengthened by the purchase of both Atla and ProQuest religion databases. We discovered about six years ago that the limitations on staff access to franchising HE digital collections was a hindrance to good pedagogical practice and so committed to the costs of these databases as a means of ensuring parity of access across students and faculty. Subsequently, this 
has placed us in a strong position when moving to the OU, who do not provide e-resources to their franchise partners. There are other resources I would like to subscribe to, but currently cost precludes further expansion. However, a variety of free journal gateways have been identified and linked through the UST VLE.

Before moving on to areas relating to copyright, information literacy, etc., I would like to consider the "cash value," as it were, of my brief historical narrative:

1) Build strong relationships with faculty. They may well have knowledge of resources and access strategies that you and the students do not. They can also vet materials and e-resources you may discover for yourself regarding relevance, etc.

2) Develop strong relationships with mentors; there are several benefits:

a) They are the primary support person for the students in the LCs. If well-informed and familiar with support facilities, they may well filter out the easy-to-handle issues of resource support, leaving the librarian only with those that are particularly tricky.

b) Their own skill sets can be developed, benefiting them not only as they mentor institutional students but also in terms of their own development as learners and in their ministries.

c) They can provide an early warning system for major issues and a pool of consultants who, knowing what is happening on the ground, can critically inform and assess new support from the centre.

3) As an institutional librarian, take time to link to blogs, use social media, and read your journals to identify relevant resources. Social media is particularly good at pointing up free high-quality resources-for example, Chad Van Dixhoorn's site on the Westminster Assembly-and, as I have already noted, make use of Theology-on-the-Web!

4) It is also worthwhile, in making a case to management, to use the theological library networks to run surveys across institutions to generate benchmark data regarding subscription-based resources. We have, in the past, relied on the provision through HE franchise partners, but this is becoming 
increasingly limited, and we all face a requirement to supply commercial, digital resources directly; increasingly a necessity rather than a luxury, even for campus-based students. At a seminar a couple of years ago, the librarian from Cardiff Metropolitan University demonstrated the greater reach and impact of digital resourcing as compared to print resourcesif I remember correctly, by a factor of something between 5 and 10 times.

\section{COPYRIGHT}

Copyright is a major issue in supporting DL, particularly in the model we have developed at UST. Naturally, students tend to be ignorant of the finer points of correct practice and can collectively be quite inventive at circumventing difficulties they find in access. Essentially, all the distance students are subject in the use they make of digitization to British regulations. This inevitably means that students in the same LC may only collectively receive one copy of any particular item and that care must be taken in assessing who is requesting successive segments of core texts-I am absolutely convinced that, several years ago, one LC managed to obtain an entire book digitally by each student requesting a different chapter. The issue came to light during a review of provision and, in subsequent years, great care has been taken to ensure that it doesn't happen again. Without a definitive "public" guide, I am probably more cautious than necessary in controlling this aspect of DL support.

\section{STUDENT RESEARCH SKILLS}

Student research skills programmes have been established as part of the personal development programme of UST's provision. Prior to my appointment, there had been no impetus to formally equip our students with IL skills as independent learners for lifelong study, despite the recognition that the best pastors and ministers need such ability, and increasingly so, as was noted at the LILAC conference in 2011. As a conference report noted,

The first keynote speaker, Professor David Nicholas, described the move away from researching in the library to researching online, anywhere in the world, at all times of 
day, and completely unsupported. Information professionals need to re-embed themselves in peoples' research behaviour, and this means getting there first. (Harvey 2011, 89).

The 2015 LILAC conference offered complimentary perspectives,

Barbara Fister's keynote . . . expanded upon this thinking, stating that part of librarians' role in education is to encourage learners to change their relationship with information, to understand the social nature of sources and place their ideas within that context. . . . Critical IL empowers learners and gives them the freedom to deviate, enabling them to discover and create knowledge within and beyond formal education. (Nagle 2015, 108)

These perspectives underpin the programme in which campus students receive four sessions of formal teaching alongside the more informal guidance offered on an ad hoc basis, and the option of booking formal research tutorials with the librarian. Clearly, such face-toface provision is not necessarily accessible by the LC-based students, who, as the network extends, may be meeting at times when the school is closed (we already need to timetable with care for the LCs in North America), but is just as critical for their on-course performance and future ministries.

Our academic year starts with a conference to which mentors and students are encouraged to come. As part of that programme, a basic orientation session on the library is provided and, as far as possible, this is reinforced by individual conversations with mentors at which issues like digitization, copyright, and ILL are discussed. Inevitably, there are issues in the longer-term implementation of the advice as time and demands of ministry, etc. impact the life and work of the LCs. A satisfactory method of reinforcement and updating is need, but as yet undeveloped.

To address student research skill needs in the LCs an online, selfdirected tutorial on the practical aspects of locating resources has been developed. The original had been developed by the University of London, so, having obtained their agreement, I re-skinned and adapted it to fit our context. The initial version proved clunky and unsatisfactory owing to the web platform used, so it was removed, but the growing need of the LCs generated a need to provide a newer iteration, giving the opportunity to check and correct broken links as well as revise the OS and appearance. This is available via the Union 
Digital Library pages to all students. However, such mechanisms on their own are not enough; the librarian as facilitator/mentor, embedded into online delivery, has proven very effective in supporting and developing students engaged in online and independent learning (Kumar and Edwards 2013, 3). This has yet to be addressed as part of the tutorial, but mechanisms such as "Ask the Librarian" pages in the tutorial may address the issue of embedding human interaction in what is otherwise a digital environment.

The taught programme will also be made available through videos. An early attempt at producing the videos has failed to meet the necessary quality standard for all the reasons I have already outlined in relation to teaching videos, but the plan is to make these sessions available through the VLE (they have already been recorded) in time for the September 2020 start at the latest.

\section{TECHNOLOGY}

Although issues of time zones affect some of the LCs as already noted, work on widening the Greek-language delivery of the school has enabled a widening of access to live teaching on campus for the LCs. Skype offers options for individual support but has proved limited in relation to multiple participation across several centres. However, the Zoom facility has proved highly successful, and I plan to explore how this might be used as a mechanism for "live" IL classes with LCs.

\section{CONCLUSION}

Digital solutions are clearly the only practicable way forward for a small (at least in staff terms) library to service the needs of a diverse and geographically globally scattered student body. Thornes (2012, 93), reporting on online literacy tutorials, noted a number of factors that cover issues around resource provision as well,

- Is this the most appropriate method of delivery to meet the needs of the students?

- How will elements for interaction and reflection be incorporated?

- How will the design allow for a balance between content and look and feel?

- How much time is required for the development? 
- Who is the most appropriate person to create the resource, in terms of skill set, time, and money?

- How will feedback be obtained, especially when there is no impetus for students to provide this?

- What are the options for collecting statistical data on usage?

- Can it realistically be maintained over a longer period of time?

One of the strengths of the UST LC model is that students can discuss and reflect in the group situation that which they have studied individually - an advantage that has been noted in IL literature (Webster and Whitworth 2017, 72-3). We are not there yet in the DL support the library offers but will hopefully, as I draw on both theory and our own experience in subject teaching through Zoom and other means, build structures that offer the GDip students working in the LCs a real equivalence of learning support and opportunity.

All of this is only achievable if we are seen by our institutions and faculty as partners in the educational process and not merely technical support ancillary, and inferior to, the business of teaching. If a theology department or seminary is truly committed to preparation for a life of ministry, it must see the requirement not simply to provide foundations in theology but to equip the students to be lifelong learners with skills of criticality with respect to the information environment and understanding of the range and validity of sources they face. Librarians bring skillsets that support and develop such understanding as fellow educationalists and with a rich resource of experience and practice mediated through professional organisations like ABTAPL and Atla and through professional literature of the sort I have cited here. Can I encourage you all, whether serving DL communities or not, to lobby for this recognition (if you do not already have it) within your own institutions?

\section{WORKS CITED}

Harvey, M. 2011. "LILAC Goes to London. Journal of Information Literacy, 5, no. 1: 89-90. ojs.lboro.ac.uk/JIL/article/view/ CC-V5-I1-2011-1/1887.

Kumar, S. and M. Edwards. 2013. "Information Literacy Skills and Embedded Librarianship in an Online Graduate Programme.” 
Journal of Information Literacy 7, no. 1: 3-17. ojs.lboro.ac.uk/JIL/ article/view/PRA-V7-I1-2013-1/1791.

Nagle, M. 2015. "Where the Buses Don’t Run: A LILAC 2015 Conference Report.” Journal of Information Literacy 9, no. 1: 108-10. ojs. lboro.ac.uk/JIL/article/view/CC-V9-I1-5/2144.

Thornes, Sara L. 2012. "Creating an Online Tutorial to Support Information Literacy and Academic Skills Development.” Journal of Information Literacy 6, no. 1: 82-95. ojs.lboro.ac.uk/JIL/article/ view/LLC-V6-I1-2012-3/1749.

Webster, L. and A. Whitworth. 2017. "Distance Learning as Alterity: Facilitating the Experience of Variation and Professional Information Practice.” Journal of Information Literacy 11, no. 2: 69-85. ojs.lboro.ac.uk/JIL/article/view/PRA-11-2-4/2575. 